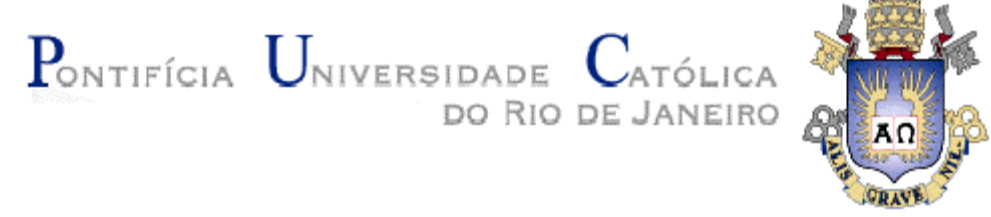

Camila Rodrigues Leite

\begin{abstract}
O Grupo "Nós na Fita"
Análises de uma prática mídia-educativa protagonizada por jovens moradores do Morro Preventório
\end{abstract}

Dissertação de Mestrado

Dissertação apresentada como requisito parcial para obtenção do grau de Mestre pelo Programa de Pós-Graduação em Educação do Departamento de Educação da PUC-Rio.

Orientador: Prof. Rosália Duarte 


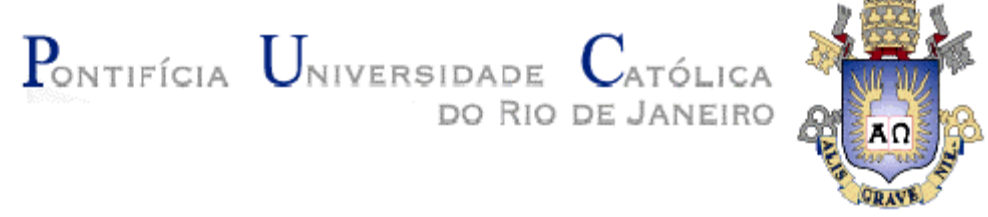

Camila Rodrigues Leite

\begin{abstract}
O Grupo "Nós na Fita"
Análises de uma prática mídia-educativaprotagonizada por jovens moradores do Morro Preventório
\end{abstract}

\begin{abstract}
Dissertação apresentada como requisito parcial para obtenção do grau de Mestre pelo Programa de Pós-Graduação em Educação do Departamento de Educação do Centro de Teologia e Ciências Humanas da PUC-Rio. Aprovada pela Comissão Examinadora abaixo assinada.
\end{abstract}

Prof. Rosália Duarte

Orientadora

Departamento de Educação - PUC-Rio

Prof. Vera Maria F. Candau

Departamento de Educação - PUC-Rio

Prof. Rita Marisa Ribes Pereira

UERJ

Prof. Paulo Fernando C. de Andrade Coordenador Setorial do Centro de Teologia e Ciências Humanas

Rio de Janeiro, 01 de abril de 2005 
Todos os direitos reservados. É proibida a reprodução total ou parcial do trabalho sem autorização da universidade, doa autora e do orientador.

\section{Camila Rodrigues Leite}

Graduou-se em Pedagogia pela PUC-Rio em 2002. Desde 2003

é pesquisadora do Grupo de Pesquisa em Educação e Mídia (GRUPEM - PUC-Rio). Desde 1998, trabalha no campo da arte-educação desenvolvendo projetos sociais.

Ficha catalográfica

Leite, Camila Rodrigues

O Grupo "Nós na fita": análise de uma prática mídiaeducativa protagonizada por jovens moradores do Morro Preventório / Camila Rodrigues Leite ; orientador: Rosália Duarte. - Rio de Janeiro : PUC-Rio, Departamento de Educação, 2005.

$160 \mathrm{f.} ; 30 \mathrm{~cm}$

Dissertação (mestrado) - Pontifícia Universidade Católica do Rio de Janeiro, Departamento de Educação .

Inclui bibliografia

1. Educação - Teses. 2. Educação não-formal. 3. Mídia-educação. 4. Juventude. 5. Vídeo comunitário. I. Duarte, Rosália. II. Pontifícia Universidade Católica do Rio de Janeiro. Departamento de Educação. III. Título. 


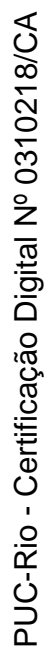

Para o Grupo "Nós na Fita". 


\section{Agradecimentos}

Ao grupo Nós na Fita: Daniela, Robert, Ana Paula, Keyla, Luciano, e Adriana que se tornaram os personagens principais desta história. Esta dissertação justifica-se pela existência de cada um de vocês e, principalmente, pelo trabalho coletivo que esses "nós tecem nas fitas". Eternamente grata por terem compartilhado comigo suas vidas, desafios e conquistas. Com vocês, aprendi muito!

Aos alunos da Oficina de TV e vídeo 2004: Thaís, Dávila, Phelipe, Ramiro, Gerlânia, Camila, Helen, Gabriel, Vinícius, Ludmila, Daniele, Gabriela e Rafael por também terem se tornado personagens desta história.

À Bem TV, na figura da Márcia e da Olívia, que prontamente me acolheram e abriram as portas da instituição para me receber. Grata por terem me proporcionado conhecer de perto um trabalho de tanta qualidade.

À minha orientadora, Rosália Duarte, por tudo que me ensinou, por todas às vezes que me indicou o caminho das pedras, por tudo que representa na minha vida, por tudo que compartilhamos juntas. Eternamente grata pelo nosso encontro, amizade, cumplicidade, carinho e respeito.

Ao João Alegria, pelo encontro, pela parceria, pela leitura cuidadosa do meu texto, por suas imprescindíveis contribuições e pela crença nos sabores e saberes do trabalho com mídia-educação.

Aos companheiros do Grupo de Pesquisa em Educação e Mídia - GRUPEM Rita, Cris, Gal, Gleice, Lívia, Laudelina, Adriana, Marinete e Carlos pela possibilidade de troca e construção coletiva de conhecimentos. Aquela prévia da defesa foi muito importante para a finalização deste trabalho.

À Rita Ribes e Vera Candau que, desde o início, se dispuseram a dialogar com este trabalho. 
À minha mãe, Marcia Leite e a meu pai, Aristeo Leite, por absolutamente tudo!

Eternamente grata, pelo apoio, carinho e amor incondicional. Não há palavras que dêem conta da minha gratidão.

Aos meus avós, Edir, Ivo e Aristeo, que acolheram-me redimensionando o sentido da vida. Grata por tudo que representam e pelos maravilhosos momentos que vivemos juntos.

Aos meus irmãos, Jonas e Evandro, por serem pessoas tão especiais. Amo vocês, a cada dia mais.

À Luana, amiga de todas as horas, por nossa cumplicidade e companheirismo. Grata pelo incondicional apoio, carinho e amor.

À Ilana, pela simplicidade da luz de sua alma que, nos momentos mais difíceis, me animou, nutrindo minhas fortalezas.

Às amigas do peito, irmãs de coração, Betha, Mari, Clara Albano e Clarice Saliby, por existirem em minha vida e terem me feito sorrir nos momentos difíceis. Ah, não posso deixar de agradecer o "kit para sobreviver a uma dissertação", talvez sem ele não tivesse chegado ao fim.

À Mercedes Clara, hermana del ama, companheira da vida intera, que, mesmo a distância, ressignificou a caminhada, trazendo luz, música e confiança.

À Diana, que, durante todo o percurso, alimentou minha coragem para seguir em frente.

Ao professor Pier Cesar Rivoltella, pelas dicas.

Ao Cadinho, que me apresentou à Bem TV e o Nós na Fita.

À Denise, que, diante do caos, sempre me mostra a luz. Serei eternamente grata por ter te encontrado nesta vida.

A toda equipe do TEAR, em especial, à Cacau, Claudinha, Cacá, Mabel, Beto e Marisa pelo constante apoio e carinho. 
Aos adolescentes do Ciranda Brasileira, que se tornaram fonte de inspiração, me fazendo não abrir mão do trabalho com a arte-educação.

Aos adolescentes e crianças participantes da Oficina TVE de Mídia 2003 e 2004, pela oportunidade de vivenciar junto com vocês uma prática mídia-educativa.

À Orquídea, pelo incansável trabalho de me organizar internamente.

À Nilza, pela simplicidade e grandeza da sua sabedoria. O que seria de mim se não fosse sua comida e seu saboroso café no final da tarde!

Ao André, que no caminho se tornou amigo de alma e de utopia.

Ao Sérgio, que, aos “45 do segundo tempo", me ajudou a fazer um vídeo a partir deste trabalho.

À Lindara e ao Fabio, por tudo que vivemos juntos.

Aos companheiros da pós-graduação, em especial Dani, Pablo e Tetê.

A Deus, aos Deuses e Deusas, aos Orixás, aos anjos e aos seres de luz, que, sempre ao meu lado, iluminaram, abençoaram, protegeram e guiaram o caminho.

A todos os professores do Departamento de Educação da PUC-RIO, que, desde a graduação, tornaram-se meus mestres neste percurso.

À PUC-Rio, que, desde 1998, tornou-se território de muitas aprendizagens.

Ao $\mathrm{CNPq}$ e a FAPERJ, que viabilizaram financeiramente este processo de pesquisa. 


\section{Resumo}

Leite, Camila Rodrigues; Duarte, Rosália. O Grupo “Nós na Fita" análises de uma prática mídia-educativa protagonizada por jovens moradores do Morro do Preventório. Rio de Janeiro, 2005. 169p. Dissertação de Mestrado - Departamento de Educação, Pontifícia Universidade Católica do Rio de Janeiro.

Este trabalho teve como ponto de partida os debates sobre práticas educativas que vêm sendo desenvolvidas no campo da mídia-educação; um campo ainda em configuração. Destacam-se aqui, as experiências desenvolvidas por Organizações Não-Governamentais, no âmbito da educação não-formal, que envolvem jovens, moradores de comunidades urbanas de baixa renda, no processo de realização de vídeos comunitários. A partir da análise de observações, entrevistas e vídeo-gravações, produzidas ao longo do trabalho de campo, descreve-se e se analisa a prática mídia-educativa desenvolvida pela ONG Bem TV e protagonizada pelos jovens do grupo Nós na Fita. O estudo centrou-se especificamente na Oficina de TV e Vídeo 2004, realizada no Morro do Preventório, em Niterói, no Estado do Rio de Janeiro. Orientam este trabalho, as reflexões levantadas por Martín-Barbero a respeito da comunicação alternativa, participativa e popular, do uso social dos meios e dos processos de mediações que articulam comunicação, cultura e política na América Latina.

\section{Palavras-chave}

Educação não-formal; mídia-educação; juventudes; vídeo comunitário. 


\section{Abstract}

Leite, Camila Rodrigues; Duarte, Rosália (Advisor). Nós na Fita'group: analising of a media education practice. Rio de Janeiro, 2005. 169p. MSc. Dissertation - Departamento de Educação, Pontifícia Universidade Católica do Rio de Janeiro.

This study started off with the debates on educational practices being undertaken in the field of education-media, a field still in its early stages of development. The experiences realized by non-governmental organizations in the scope of informal education, involving young residents of low income communities in the making of community videos, was the main focus of this project. Taking into consideration the analysis of observations, interviews and videos produced during field work, the education media practices developed by the non-governmental organization "Bem TV" and carried out by the youths of the "Nós na Fita" group were analyzed and described in detail. The study focused primarily on the "Oficina de TV e video 2004" that took place at the Morro do Preventório, located in the city of Niterói, state of Rio de Janeiro. The study was based on the thoughts and reflections of Matín-Barbero regarding alternative, engaging and popular communication, the social use of the mass and processes of mediation that articulate communication, culture and politics in Latin America.

\section{Key words}

Media Education, No formal education, Media education Practices, Youth. 


\section{Sumário}

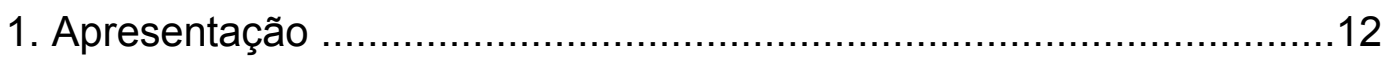

2. Primeira Parte: O percurso da pesquisa ………............................16

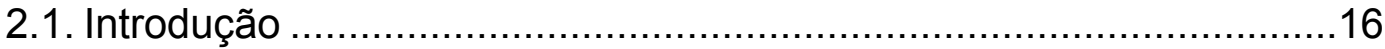

2.2. Mídia-Educação como campo de estudos e práticas ……...............18

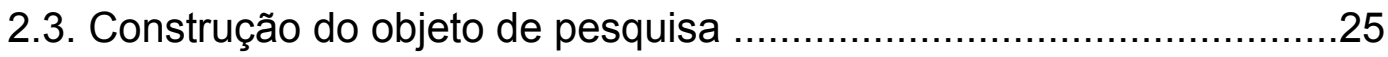

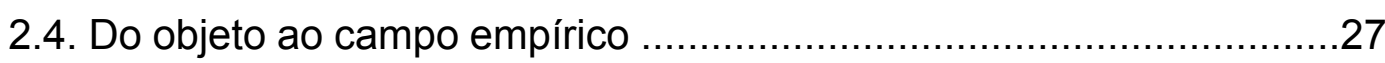

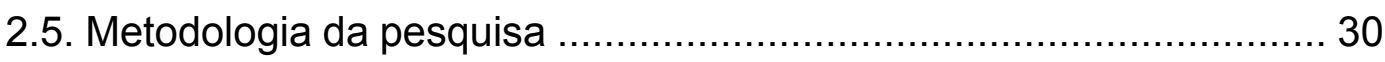

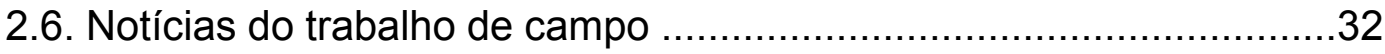

2.7. A entrada da câmara - uma nova forma de olhar .............................33

3. Segunda Parte: Apresentação do caso estudado .................................35

3.1. O Cenário - Morro do Preventório .................................................35

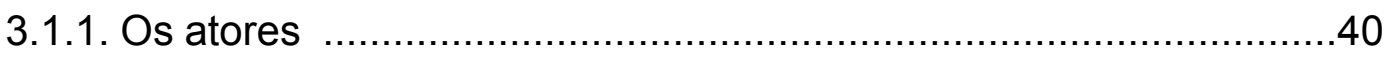

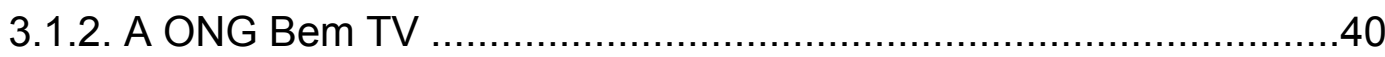

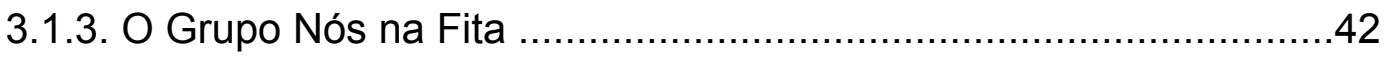

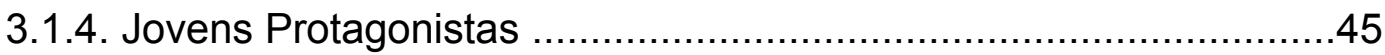

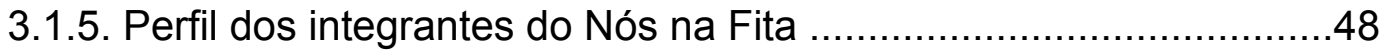

4. Terceira Parte: $O$ trabalho de campo e algumas reflexões sobre a

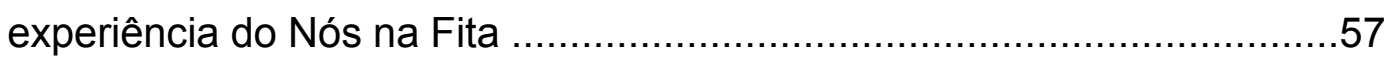

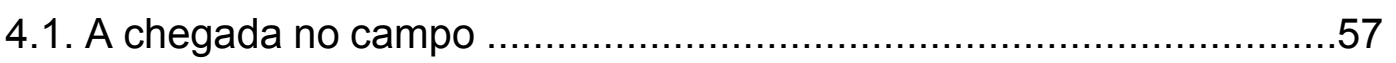

4.2. Nós na Fita: comunicação / cultura / política ....................................61

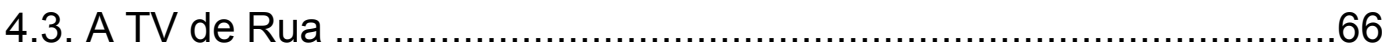

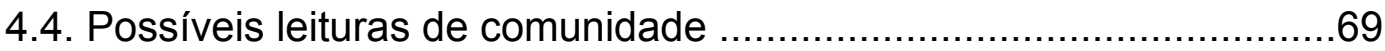

4.5. Comunicação comunitária, participativa, alternativa e popular .........73

4.6. As instâncias de mediação: tecnicidade, ritualidade, sociedade e

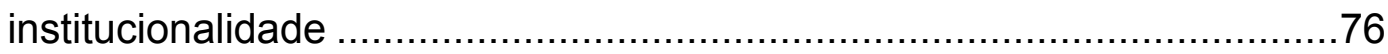

4.7. Entre orientação e tutela: tensões no processo de construção da

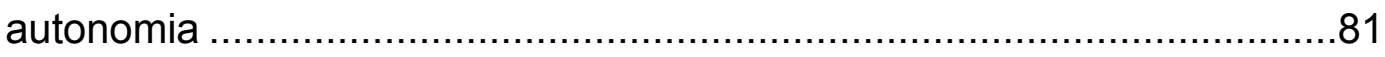

4.8. Entre o Preventório e o mundo: seduzidos pela criação ………........85 
5. Quarta Parte: Análises de uma prática mídia-educativa protagonizada

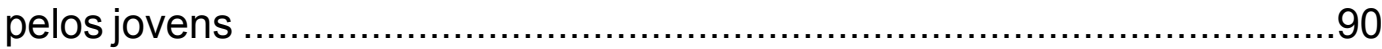

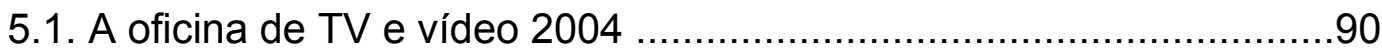

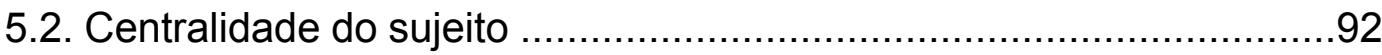

5.3. Capacitação técnica e mobilização social em tensão: o papel das ONG's .95

5.4. Uso social dos meios? Entre o objetivo da oficina e o desejo dos alunos 100

5.5. Os alunos podem fazer os vídeos que quiserem? 106

5.6. Colocando a mão na massa: reflexões sobre a produção dos alunos 109

5.7. Mão na Massa 2: algumas atividades 112

5.8. Trabalho em grupo. Construção coletiva de conhecimentos 115

5.9. Afinal quais seriam os temas dos vídeos dos alunos? 117

5.10. Criação sob uma lente grande angular 121

5.11. Mídia-educação: diferentes perspectivas em conflito 143

5.12. Mídia-educador 146

6. Considerações Finais 149

6.1. Os desafios e aprendizados do fazer pesquisa 149

6.2. Contribuições desta pesquisa para as reflexões no campo da mídiaeducação 151

7. Referências Bibliográficas 155

Anexos. 